\title{
Tetrahydrocurcumin alleviates hypertension, aortic stiffening and oxidative stress in rats with nitric oxide deficiency
}

\author{
Saowanee Nakmareong ${ }^{1}$, Upa Kukongviriyapan ${ }^{1}$, Poungrat Pakdeechote ${ }^{1}$, Veerapol Kukongviriyapan ${ }^{2}$, \\ Bunkerd Kongyingyoes ${ }^{2}$, Wanida Donpunha ${ }^{1}$, Parichat Prachaney ${ }^{3}$ and Chada Phisalaphong ${ }^{4}$
}

Tetrahydrocurcumin (THC), a major metabolite of curcumin, possesses strong antioxidant and cardioprotective properties. However, the activities of THC in hypertension and its associated complications remain unknown. The aim of this study was to investigate the effect of THC on hemodynamic status, aortic elasticity and oxidative stress in rats with $\mathrm{N}$-nitro-L-arginine methyl ester (L-NAME)-induced hypertension. Hypertension was induced in male Sprague-Dawley rats by administration of L-NAME ( $50 \mathrm{mg} \mathrm{kg}^{-1}$ body weight) in drinking water for 5 weeks. THC at a dose of 50 or $100 \mathrm{mg} \mathrm{kg}^{-1}$ per day was administered daily during the fourth and fifth weeks when the hypertensive state had been established. The effects of THC on hemodynamics, aortic elasticity, endothelial nitric oxide synthase (eNOS) protein expression and oxidative stress markers were assessed. Marked increases in blood pressure, peripheral vascular resistance, aortic stiffness and oxidative stress were found in rats after L-NAME administration. THC significantly reversed these deleterious effects by reducing aortic wall thickness and stiffness. These effects were associated with increased aortic eNOS expression, elevated plasma nitrate/nitrite, decreased oxidative stress with reduced superoxide production and enhanced blood glutathione. Our results provide the first evidence that THC attenuates the detrimental effect of L-NAME by improving the hemodynamic status and aortic elasticity concomitant with reduction of oxidative stress. The present study suggests that THC might be used as a dietary supplement to protect against cardiovascular alterations under nitric oxide-deficient conditions.

Hypertension Research (2012) 35, 418-425; doi:10.1038/hr.2011.180; published online 10 November 2011

Keywords: aortic elasticity; L-NAME; nitric oxide; oxidative stress; tetrahydrocurcumin

\section{INTRODUCTION}

Hypertension is associated with changes in endothelial and vascular smooth muscle cell structure and function. It is widely accepted that nitric oxide (NO) plays a central role in protecting the cardiovascular system against hypertension and injury. $\mathrm{N}$-nitro-L-arginine methyl ester (L-NAME), an L-arginine analogue, is the most frequently used NO synthase inhibitor in experimental animals. Chronic administration of L-NAME results in systemic arterial hypertension accompanied by an increased vascular resistance and decreased blood flow in various organs. ${ }^{1}$ Moreover, it has been reported that NO synthase inhibitors have an effect on large arterial stiffness resembling that of chronic hypertension. ${ }^{2}$ Therefore, chronic NO deprivation causes not only hypertension but also vascular remodeling, which is an adaptive response to the increased hemodynamic load within the vascular wall.

It has been well established that reduction in NO synthesis increases endothelial intracellular oxidative stress in animals. Several lines of evidence suggest that enhanced reactive oxygen species production is involved in the pathogenesis of the NO-deficient hypertensive model. Therefore, a unifying characteristic of L-NAME-induced hypertension is the presence of oxidative stress that participates in the maintenance of elevated arterial pressure and seems to be a common denominator underlying endothelial dysfunction in this model of experimental hypertension. ${ }^{3}$ It has been demonstrated that nitric oxide synthase inhibition leads to increased accumulation of superoxide $\left(\mathrm{O}_{2}^{\bullet-}\right)$ generation, ${ }^{4}$ activation of NADPH oxidase, ${ }^{5}$ increased malondialdehyde concentrations in the heart and aorta ${ }^{6}$ and enhanced vascular thromboxane B2 synthesis, ${ }^{7}$ whereas the activities of antioxidant enzymes such as plasma superoxide dismutase ${ }^{8}$ and hepatic glutathione peroxidase are reduced. ${ }^{7}$ Moreover, it is found that overproduction of reactive oxygen species modulates vascular structure and function in several ways, including damaged endothelial and vascular smooth muscle cells, altered redox state and increased intracellular free calcium concentration. ${ }^{9}$ Therefore, increased oxidative stress caused by NO deficiency may significantly contribute to the development of hypertension. 
Curcumin is a phenolic compound extracted from the powdered dry rhizome of Curcuma longa Linn. Several pharmacological properties of curcumin have been reported, including neuroprotective, hepatoprotective, anticarcinogenic, anti-inflammatory and antioxidant effects. ${ }^{10}$ Tetrahydrocurcumin (THC) is one of the major metabolites of curcumin, which presents the same phenolic and $\beta$-diketo moieties as curcumin. THC has been reported to exhibit similar pharmacological properties as to curcumin. Previous studies have demonstrated that THC exhibits antioxidant activity by inhibiting the peroxidation of membrane lipid. ${ }^{11}$ Additionally, an in vitro study has reported that THC possesses stronger antioxidant properties than curcuminoids, including curcumin, demethoxycurcumin and bisdemethoxycurcumin, suggesting that hydrogenation at the conjugated double bonds of the central seven-carbon chains is important for this activity. ${ }^{12}$ Supplementation with THC reduces thiobarbituric acid reactive substance concentration in the liver and kidney of rabbits fed with a high cholesterol diet. ${ }^{13}$ THC showed protective effects against oxidative stress by enhancing activities of key endogenous antioxidant enzymes, including superoxide dismutase, catalase and glutathione peroxidase, whereas it decreased thiobarbituric acid reactive substance and hydroperoxide formation. ${ }^{14,15}$ Moreover, THC has shown cardioprotective effects by reducing the infarction size in an ischemic-reperfusion model of myocardial infarction. ${ }^{16}$ This effect was associated with reduced lipid peroxidation and improved antioxidant status. Therefore, antioxidants may be beneficial for cardiovascular protection, especially against hypertension by a decrease in oxidative load in the vascular system.

Although THC has been reported to possess strong antioxidant activity, both in vivo and in vitro, information about its beneficial effects on the cardiovascular system is scarce. L-NAME-induced hypertension is a common model of experimental hypertension in animals and the model also demonstrates aspects of the chronic hypertensive state including changes in vascular structure. The present investigation was thus carried out to investigate whether THC could ameliorate the detrimental effect of L-NAME on hemodynamic disturbance and aortic stiffness in association with oxidative stress in rats by L-NAME-induced hypertension.

\section{METHODS}

Chemicals

THC (purity $>99 \%$ w/w by high-performance liquid chromatography) was synthesized and provided by the Government Pharmaceutical Organization, Bangkok, Thailand. L-NAME, 5,5 dithio-bis-2-nitrobenzoic acid, EDTA, thiobarbituric acid, sodium dodecyl sulfate, glutathione (GSH), butylated hydroxytoluene, sulfanilamide dinitrophenylephrinenylhydrazine, $N$-1-nepthylethylenediamine dihydrochloride, 1,1,3,3-tetraethoxypropane, bromophenol blue, 2-mercaptoetanol and guanidine were purchased from Sigma-Aldrich Corp. (St Louis, MO, USA). Nitrate reductase, nicotinamide adenine dinucleotide phosphate (NADPH) and glucose-6-phosphate dehydrogenase were obtained from Roche Applied Sciences (Mannheim, Germany). Trichloroacetic acid, metaphosphoric acid, 1-methyl-2 vinyl-pyridinum trifate, lucigenin, Tween and skimmed milk were obtained from Fluka Chemika (Buch, Switzerland). Mouse monoclonal anti-endothelial nitric oxide synthase (eNOS) was obtained from BD Transduction Laboratory (San Jose, CA, USA). Anti-mouse IgG antibody was purchased from Santa Cruz Biotechnology (Santa Cruz, CA, USA). All other chemicals used were of analytical grade quality.

\section{Animals}

The procedures and experimental protocols were reviewed and approved by the Institutional Animal Ethics Committee of Khon Kaen University (AEKKU01/ 2551). Adult male Sprague-Dawley rats weighing 200-220 g were obtained from the Animal Care Unit of The Faculty of Medicine, Khon Kaen University (Khon
Kaen, Thailand). All rats were housed under constant temperature in a room with a 12-h light-dark cycle. They were fed with a standard chow diet (Chareon Pokapan Co. Ltd., Thailand).

After 1 week of acclimatization, hypertension was induced in the rats by administering L-NAME $\left(50 \mathrm{mg} \mathrm{kg}^{-1}\right.$ per day) in their drinking water for 5 weeks. After 3 weeks, hypertension had been established and was sustained in all animals. During the last 2 weeks, L-NAME hypertensive rats were randomly divided into three treatment groups $(n=8-10$ per group). Group 1 was intragastrically administered with polyethylene glycol, a THC vehicle, for 2 weeks. Group 2 and 3 were intragastrically administered with THC for 2 weeks at doses of 50 and $100 \mathrm{mg} \mathrm{kg}^{-1}$ per day, respectively. The age-matched rats received tap water ad libitum and the intragastrically administered polyethylene glycol group served as the normotensive control group. Systolic blood pressure (BP) was measured weekly in conscious rats using the noninvasive method of tail cuff plethysmography (BP analyzer, model 129, IITC, Woodlandhills, CA, USA)

\section{Measurement of the hemodynamic status}

To determine resting baseline $\mathrm{BP}$ and heart rate, the animals were anesthetized with an i.p. injection of ketamine $\left(100 \mathrm{mg} \mathrm{kg}^{-1}\right)$ and xylazine $\left(10 \mathrm{mg} \mathrm{kg}^{-1}\right)$. Body temperature was maintained at $37 \pm 2{ }^{\circ} \mathrm{C}$ throughout the measurement period with a heating pad. A tracheotomy was performed and the animals were allowed to breathe spontaneously. The femoral artery was catheterized with polyethylene catheters filled with heparinized saline and connected to a pressure transducer for continuous monitoring of BP and heart rate using Acqknowledge data acquisition analysis software (BIOPAC Systems Inc., Goleta, CA, USA). Baseline values of BP and heart rate were monitored for $20 \mathrm{~min}$, and a second polyethylene catheter was inserted into the femoral vein to allow i.v. drug delivery. Subsequently, hindlimb blood flow was continuously measured by opening the abdominal cavity below the kidneys and placing an electromagnetic flow probe around the abdominal aorta connected to an electromagnetic flowmeter (Carolina Medical Electronics Inc., East Bend, NC, USA), Hindlimb weight was obtained by cutting the hindlimb of the rat and weighing. Hindlimb vascular resistance was calculated from mean arterial pressure and hindlimb blood flow in $100 \mathrm{mg}$ tissue units. At the end of the experimental period, rats were killed by overdose of an anesthetic drug. Blood samples were withdrawn from the abdominal aorta into EDTA tubes for the assay of oxidative stress and antioxidant markers. The thoracic aorta and carotid arteries were rapidly excised from the animal and used for analysis of eNOS protein expression and $\mathrm{O}_{2}{ }^{-}$production, respectively. In a separate set of experiments, the static elastic properties of animals in all groups were measured in situ after the animals were killed by overdose of the anesthetic drug.

\section{Assessment of aortic elasticity}

The aortic elasticity was determined as previously described. ${ }^{17}$ Briefly, rats were dissected to expose the thoracic aorta. Two polyethylene catheters were inserted into the thoracic aorta, one distal to the arch and the other just below the diaphragm. The aorta was flushed with normal saline to remove any thrombi, and then a barium sulphate perfusion apparatus was attached to the thoracic cannula. The animals and the apparatus were placed underneath a video camera fitted with a macro lens. Preconditioning of the vessel was performed in order to ensure repeatability by inflating the aorta to $200 \mathrm{~mm} \mathrm{Hg}$ for $30 \mathrm{~s}$. After deflation, the aorta was inflated to pressures of $0,10,20,30,50,70,90,110$, $120,140,160,180$ and $200 \mathrm{~mm} \mathrm{Hg}$. Each pressure was maintained for $30 \mathrm{~s}$ to ensure equilibration of pressure between the perfusion apparatus and the aorta. The arterial images taken at each pressure were captured and processed with image analysis software (Image-Pro Plus, Silver Spring, MD, USA) for calculation of the external diameter of the vessel. This procedure was repeated for each inflation pressure and two diameter readings at each pressure were averaged. After completing the inflation experiment, the in-situ length of the thoracic aorta was measured and weighed.

To analyze the data obtained from the pressure-diameter experiment, Langewouters's equation ${ }^{18}$ was used to fit a smooth curve to the data points. The aortic weight and the in-situ length were used to calculate the wall thickness $(h)$ of the vessel from the equation $h=\left(D_{\mathrm{e}} / 2\right)-R_{\mathrm{i}}$, where $\mathrm{D}_{\mathrm{e}}$ is the external diameter and $R_{\mathrm{i}}$ is the internal radius. Midwall radius $\left(R_{\mathrm{m}}\right)$ was 
calculated from the equation $R_{\mathrm{m}}=R_{\mathrm{e}}-(h / 2)$, where $R_{\mathrm{e}}$ is the external radius. The wall thickness of the vessel at each pressure was normalized by dividing it by the $R_{\mathrm{m}} . R_{\mathrm{m}}$ at each pressure was normalized by dividing it by the $R_{\mathrm{m}}$ at a pressure of $0 \mathrm{~mm} \mathrm{Hg}$. The functional stiffness as expressed by the functional elastic modulus (Ep) of the aorta was examined because of its importance as a determinant of large artery function and cardiac load. Ep is a measurement of the relative change in blood vessel diameter in response to a known change in pressure. $^{19}$

\section{Assay of vascular superoxide anion production}

Vascular $\mathrm{O}_{2}^{\bullet-}$ production was measured using the lucigenin-enhanced chemiluminescence method as previously described, with some modifications. ${ }^{20}$ The carotid artery was rapidly excised, placed on ice and cleaned of the adherent fat and connective tissue. The vessel segments were cut into $3-5 \mathrm{~mm}$ length and incubated with Krebs-KCL buffer and allowed to equilibrate at $37^{\circ} \mathrm{C}$ for $30 \mathrm{~min}$. Lucigenin $100 \mu \mathrm{M}$ was added to the sample tube and placed in a luminometer (Turner Biosystems, Sunnyvale, CA, USA). The photon counts were integrated every $15 \mathrm{~s}$ for $5 \mathrm{~min}$, averaged and the respective background counts were subtracted. The vessels were dried for $24 \mathrm{~h}$ at $45^{\circ} \mathrm{C}$ and weighed. The superoxide anion production in vascular tissue was expressed as relative light unit counts per min per mg dry weight.

\section{Assay of plasma malondialdehyde}

Plasma malondialdehyde concentration was quantified as thiobarbituric acid reactive substance by a spectophotometric method as previously described ${ }^{21}$ with some modifications. ${ }^{20}$ In brief, $150 \mu$ plasma samples were reacted with $10 \%$ trichloroacetic acid, $5 \mathrm{~mm}$ EDTA, $8 \%$ sodium dodecyl sulfate and $0.5 \mu \mathrm{g} \mathrm{ml}^{-1}$ of butylated hydroxytoluene. The mixture was incubated for $10 \mathrm{~min}$ at room temperature, then $0.6 \%$ thiobarbituric acid was added, and the mixture was boiled in a water bath for $30 \mathrm{~min}$. After cooling to room temperature, the mixture was centrifuged at $10000 \mathrm{~g}$ for $5 \mathrm{~min}$. The absorbance of the supernatant was measured at $532 \mathrm{~nm}$ by spectrophotometer. A standard curve was generated with appropriate concentrations of 1, 1, 3, 3-tetraethoxypropane $\left(0.3-10 \mu \mathrm{moll}^{-1}\right)$.

\section{Assay of plasma protein carbonyl}

Oxidizing protein damage was assessed by the formation of carbonyl groups, following a previously described method ${ }^{22}$ with some modifications. ${ }^{23}$ This assay involves the derivatization of carbonyl groups with dinitrophenylhydrazine, which leads to formation of a stable dinitrophenyl hydrazone product. Briefly, plasma samples were incubated with and without dinitrophenylhydrazine in $3.6 \mathrm{M} \mathrm{HCl}$ for $1 \mathrm{~h}$ in the dark. Subsequently, protein was precipitated and then dissolved in $6 \mathrm{~m}$ guanidine. The carbonyl content was determined from the absorbance at $360 \mathrm{~nm}$ after subtraction of $\mathrm{HCl}$-treated blanks by use of a molar absorption coefficient of $22000 \mathrm{M}^{-1} \mathrm{~cm}^{-1}$. The amount of the plasma protein was analyzed by the Bradford dye-binding method.

\section{Assay of plasma nitrate/nitrite}

Accumulation of nitrate and nitrite in the blood is recognized as a measure of the oxidative products of NO. The assay of nitrate and nitrite levels was performed according to a previously described method, ${ }^{24}$ with some modifications. ${ }^{25}$ Plasma samples were deproteinized by ultrafiltration using centrifugal concentrations (Pall Corp., Ann Arbor, MI, USA). The nitrate in the supernatant was reduced to nitrite by nitrate reductase, and then the mixture was reacted with Griess solution ( $4 \%$ sulfanilamide in $0.3 \%$ napthylenediamine dihydrochloride) for $15 \mathrm{~min}$. The absorbance of samples was measured on an enzyme-linked immunosorbent assay plate reader with a filter wavelength of $540 \mathrm{~nm}$ (Tecan GmbH, Grodig, Austria).

\section{Western blot analysis}

eNOS protein expression was determined in the aortic homogenates following a previously described method ${ }^{26}$ with some modifications. In brief, the thoracic aorta was homogenized in lysis buffer. Protein samples were separated in sodium dodecyl sulfate-polyacrylamide gel by electrophoresis and transferred to polyvinylidene difluoride membranes. Membranes were incubated overnight with a monoclonal mouse antibody eNOS (1:3000 dilution; BD Transduction
Laboratory), followed by incubation with horseradish peroxidise goat antimouse IgG secondary antibody (1:2000 dilution; Santa Cruz Biotechnology) at room temperature for $2 \mathrm{~h}$. The blots were incubated in ECL substrate solution. The intensity of specific eNOS and $\beta$-actin bands were visualized and captured by Imagequant (GE Healthcare, Pittsburgh, PA, USA). The expression of eNOS protein was normalized to $\beta$-actin expression from the same sample. The data are shown as percent of normal controls.

\section{Assay of glutathione}

Assay of total glutathione in the whole blood was performed as previously described $^{27}$ and glutathione disulfide was assayed by a previously described method with some modifications. ${ }^{28}$ Briefly, $100 \mu \mathrm{l}$ of whole blood was immediately reacted with $33 \mathrm{~mm}$ 1-methyl-2 vinyl-pyridinum trifate or distilled water and subsequently treated with $5 \%$ cold metaphosphoric acid. Optical density at $412 \mathrm{~nm}$ was read 10 times at $15 \mathrm{~s}$ intervals by using a spectrophotometer (Biochrom, Cambridge, UK). A standard curve was generated by using appropriate concentrations of standard GSH. The redox ratio was calculated as GSH/glutathione disulfide.

\section{Statistical analysis}

Results are presented as mean \pm s.e.m., and $n$ refers to the number of animals used. Statistical comparisons of the differences between data were performed using one-way analysis of variance followed by Newman-Keuls post-hoc test to show specific group differences. The relationship between quantitative variables was analyzed by regression analysis (Pearson's correlation). All analyses were performed using Sigmastat software version 3.1 (Systat Software, San Jose, CA, USA). Statistical significance was determined at a level of $P<0.05$.

\section{RESULTS}

\section{Effects of THC on hemodynamic changes in L-NAME-induced} hypertension

At the beginning of the experiments, there were no significant differences in average baseline values of systolic pressure (SP) among all experimental groups (Figure 1). Administration of L-NAME caused a progressive increase in SP when compared with normal controls. The increased SP was already significant after the first week of L-NAME administration. Treatment with THC (50 and $100 \mathrm{mg} \mathrm{kg}^{-1}$ per day) at the fourth and fifth weeks reduced the increase in SP induced by L-NAME. It was noted that there was a trend of decreasing SP towards normal in the THC groups, whereas

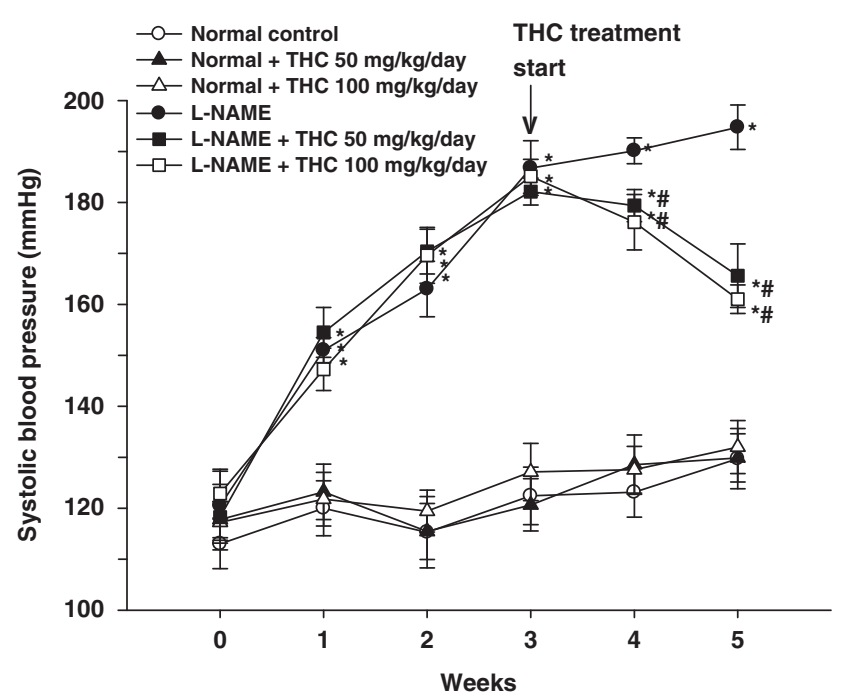

Figure 1 Effect of THC on systolic BP during L-NAME administration for 5 weeks. Results are expressed as mean \pm s.e.m. ( $n=8-10$ per group). ${ }^{*} P<0.05$ vs. normal control group, ${ }^{\#} P<0.05$ vs. L-NAME control group. 
the L-NAME control was continuing to increase with time (Figure 1). Moreover, the data showed that THC had no effect on SP in normal control rats.

Chronic L-NAME administration for 5 weeks caused persistent severe hypertension as shown by a significant increase in SP, diastolic pressure and mean arterial pressure when compared with normal controls $(P<0.05$; Table 1$)$. It is interesting that treatment with THC at 50 and $100 \mathrm{mg} \mathrm{kg}^{-1}$ per day during the last 2 weeks significantly decreased the arterial pressure in a dose-dependent manner. Although THC therapy significantly decreased the BP of L-NAME-treated rats, the $\mathrm{BP}$ of these animals was still higher than that of normotensive rats, as L-NAME induced very severe hypertension. THC at either low or high dose had no effect on the BP of the normotensive groups, suggesting that THC had no hypotensive effect on normotensive animals (Table 1). Hindlimb blood flow in L-NAME hypertensive rats was markedly lower than normal values; consequently, the calculated hindlimb vascular resistance was increased in comparison with normotensive controls. Interestingly, THC markedly decreased the hindlimb vascular resistance of L-NAME hypertensive rats $(P<0.05$; Table 1$)$. During 5 weeks of treatment, there were no significant changes in heart rates among all experimental groups (Table 1).

\section{Effects of THC on aortic elasticity}

Figures $2 \mathrm{a}$ and $\mathrm{c}$ show the relationship between pressure and aortic wall thickness. In all groups, the wall thickness of the thoracic aorta

Table 1 Effect of THC on hemodynamic status of rats in all experimental groups

\begin{tabular}{|c|c|c|c|c|c|c|}
\hline Group & $S B P(m m H g)$ & $D B P(m m ~ H g)$ & $M A P(m m ~ H g)$ & $\begin{array}{c}H R \\
\text { (beats per min) }\end{array}$ & $\begin{array}{c}\text { HBF } \\
\left(\mathrm{m} / \mathrm{min}^{-1} \text { per } 100 \mathrm{~g} \text { tissue }\right)\end{array}$ & $\begin{array}{l}\text { HVR (mm Hg min per } \\
100 \mathrm{~g} \text { tissue per } \mathrm{ml} \text { ) }\end{array}$ \\
\hline \multicolumn{7}{|l|}{ Normotensive } \\
\hline Vehicle & $129.7 \pm 5.3$ & $89.3 \pm 3.6$ & $101.8 \pm 2.7$ & $304.9 \pm 15.3$ & $8.6 \pm 0.9$ & $12.5 \pm 0.9$ \\
\hline THC $50 \mathrm{mg} \mathrm{kg}^{-1}$ per day & $126.2 \pm 2.4$ & $77.6 \pm 3.2$ & $98.5 \pm 3.0$ & $308.4 \pm 16.0$ & $8.9 \pm 0.8$ & $11.8 \pm 1.1$ \\
\hline THC $100 \mathrm{mg} \mathrm{kg}^{-1}$ per day & $124.9 \pm 3.6$ & $79.7 \pm 3.9$ & $97.8 \pm 2.8$ & $324.3 \pm 17.6$ & $8.9 \pm 0.6$ & $11.4 \pm 1.0$ \\
\hline \multicolumn{7}{|l|}{ L-NAME-induced hypertension } \\
\hline Vehicle & $218.7 \pm 3.3^{*}$ & $167.0 \pm 1.5^{*}$ & $189.8 \pm 1.9 *$ & $338.2 \pm 12.0$ & $2.7 \pm 0.5^{*}$ & $83.2 \pm 11.2^{*}$ \\
\hline THC $50 \mathrm{mg} \mathrm{kg}^{-1}$ per day & $204.0 \pm 4.0^{*, \dagger}$ & $145.8 \pm 4.0^{*, \dagger}$ & $174.1 \pm 1.7^{*, \dagger}$ & $333.6 \pm 9.8$ & $3.4 \pm 0.4^{*}$ & $55.2 \pm 8.4^{*, \dagger}$ \\
\hline THC $100 \mathrm{mg} \mathrm{kg}^{-1}$ per day & $194.3 \pm 1.6^{*, \dagger}$ & $145.2 \pm 1.5^{*, \dagger}$ & $165.5 \pm 1.8^{*, \dagger, \ddagger}$ & $303.3 \pm 14.3$ & $3.4 \pm 0.5^{*}$ & $52.2 \pm 7.8^{*, \dagger}$ \\
\hline
\end{tabular}

Abbreviations: DBP, diastolic blood pressure; HBF, hindlimb blood flow; HR, heart rate; HVR, hindlimb vascular resistance; MAP, mean arterial pressure; SBP, systolic blood pressure.

Values are expressed as mean \pm s.e.m., $\mathrm{n}=8-10$ per group.

${ }^{*} P<0.05$ vs. normal control group. ${ }^{\dagger} P<0.05$ vs. L-NAME control group. ${ }^{\ddagger} P<0.05$ vs. L-NAME treated with THU $50 \mathrm{mg} \mathrm{kg}^{-1}$ per day.
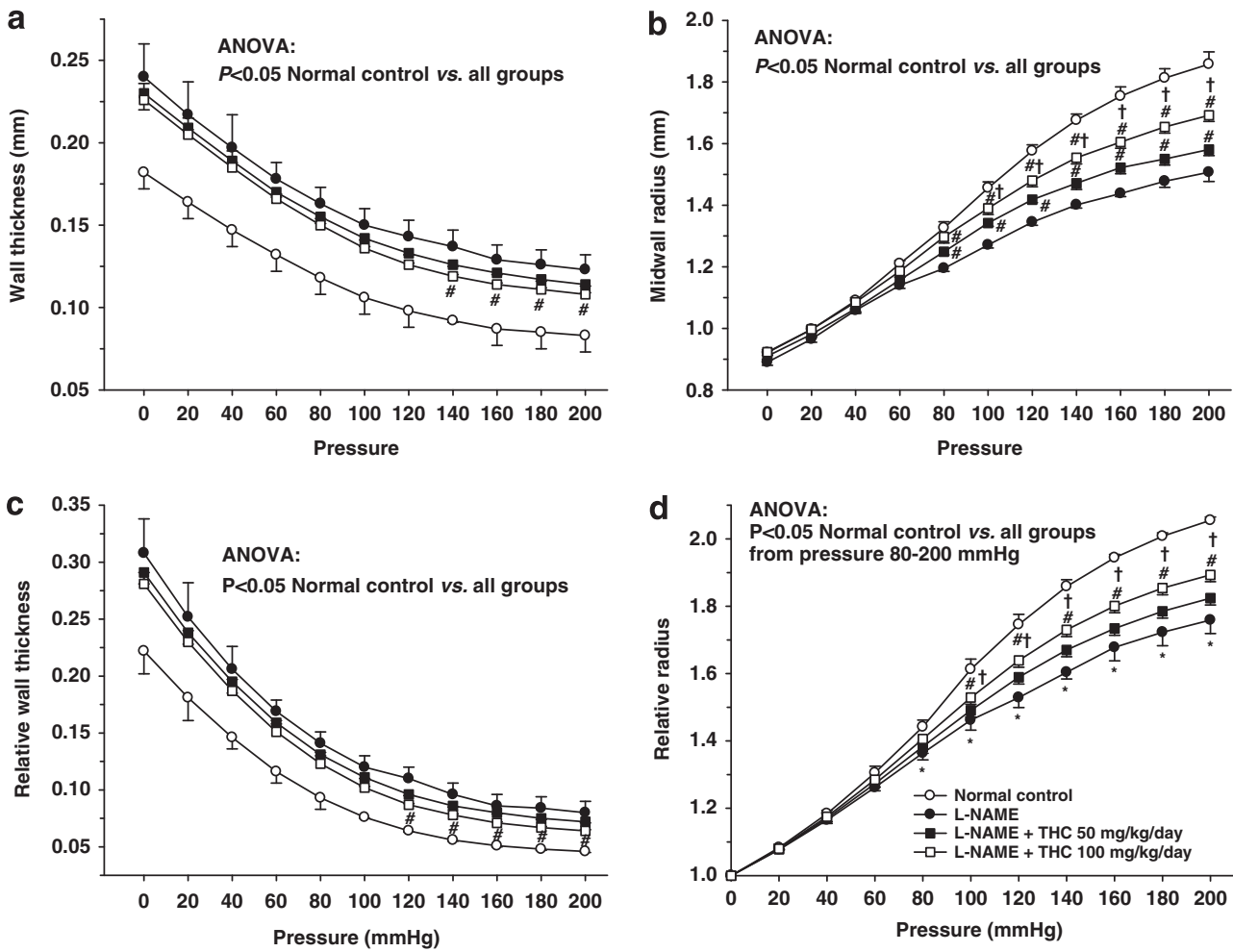

Figure 2 Effect of THC on wall thickness (a), aortic $R_{m}(\mathbf{b})$, relative wall thickness (c) and relative radius (d) of the thoracic aorta in all experimental groups. Results are expressed as mean \pm s.e.m. ( $n=6$ per group). ${ }^{\#} P<0.05$ vs. L-NAME control group, ${ }^{\dagger} P<0.05$ vs. L-NAME treated with THC 50 mg kg ${ }^{-1}$ per day. 
decreased with increasing pressure up to approximately $100 \mathrm{~mm} \mathrm{Hg}$ after which there was little change. The value of wall thickness which was obtained at a pressure of $0 \mathrm{mmHg}$ was unaffected by the pressure-radius relationship and therefore, determined only by the amount of material in the vessel wall. It was found that chronic L-NAME administration produced the development of vascular structural changes as indicated by a significant increase in wall thickness of the thoracic aorta (Figure 2a), corresponding to an increase in the relative wall thickness (the ratio of the wall thickness to radius) compared with normal controls at all pressures (Figure 2c). Treatment with THC $100 \mathrm{mg} \mathrm{kg}^{-1}$ per day was associated with a significant reduction in wall thickness (Figure 2a) and also the relative wall thickness (Figure $2 \mathrm{c}$ ). The $\mathrm{R}_{\mathrm{m}}$ and relative radius of the thoracic aorta of L-NAME-treated rats were significantly diminished at pressures within the in-vivo range when compared with normal controls, indicating a decrease in aortic compliance after L-NAME administration $(P<0.001$; Figures $2 \mathrm{~b}$ and $\mathrm{d})$. Treatment with THC ameliorated the adverse structural remodeling of the aortic wall induced by L-NAME in a dose-dependent manner, as shown by the increase in aortic compliance $(P<0.001$; Figures $2 \mathrm{~b}$ and $\mathrm{d})$.

Figure 3 shows changes in the functional elastic modulus as a function of pressure among all groups. In L-NAME hypertensive rats,

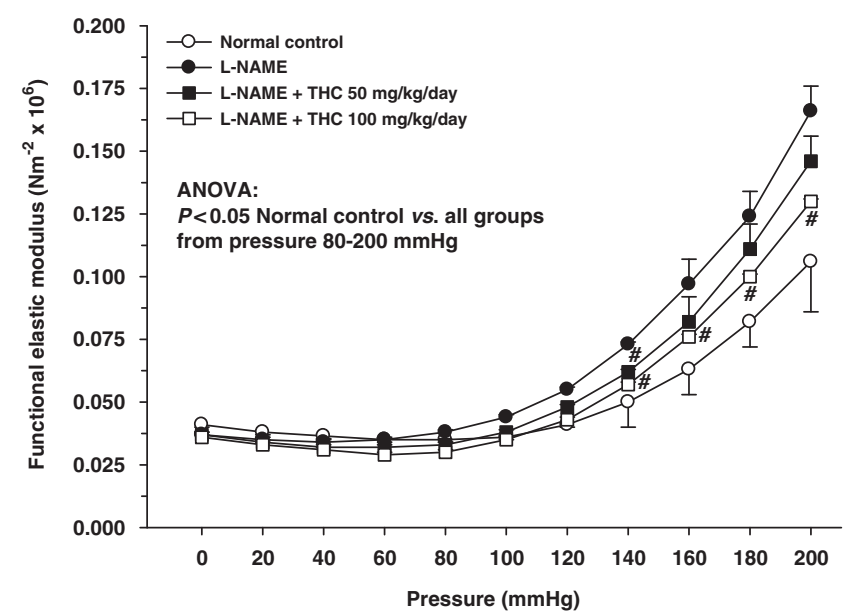

Figure 3 Effect of THC on functional stiffness of the thoracic aorta in all experimental groups. Results are expressed as mean \pm s.e.m. ( $n=6$ per group). ${ }^{\#} P<0.05$ vs. L-NAME control group. the pressure-functional modulus curve was shifted towards the left when compared with those of normotensive controls (Figure 3), showing that the aortic wall becomes stiffer after L-NAME administration. Interestingly, THC at dose of $100 \mathrm{mg} \mathrm{kg}^{-1}$ per day significantly reduced the aortic stiffness of L-NAME hypertensive rats $(P<0.05$, Figure 3). We found that administration of THC did not alter the aortic elastic properties of the normotensive rats (data not shown).

\section{Effect of THC on oxidative stress and antioxidant status}

Rats receiving L-NAME for 5 weeks exhibited high oxidative stress, which was indicated by a five fold increase in $\mathrm{O}_{2}^{\bullet-}$ production in the vascular tissues over the normotensive control rats $(P<0.05$, Table 2$)$. Treatment with THC at a dose of 50 or $100 \mathrm{mg} \mathrm{kg}^{-1}$ significantly decreased the vascular $\mathrm{O}_{2}^{\bullet-}$ production by $18 \%$ and $23 \%$, respectively (Table 2). The rate of $\mathrm{O}_{2}^{\bullet-}$ generation from vascular segments remained unchanged in normotensive rats treated with THC.

With regard to the lipid peroxidation and protein oxidation markers, we found a marked increase in plasma malondialdehyde and protein carbonyl levels in L-NAME-treated rats, and THC significantly reduced these two oxidative stress markers $(P<0.05$, Table 2). Additionally, it appeared that the antioxidant defense system was depleted in NO-deficient rats, as GSH and the ratio of GSH/ glutathione disulfide in the blood were dramatically reduced $(P<0.05$, Table 2). THC, especially at high dose, partially prevented the depletion of blood GSH and restored the redox status of L-NAMEtreated rats (Table 2). Interestingly, the alleviation of oxidative stress by THC was well correlated with the improvement in hemodynamic status, as we found a strong positive correlation between systolic BP and vascular $\mathrm{O}_{2}^{\bullet-}$ production $(r=0.925, P<0.001$, Figure 4$)$.

\section{Effect of THC on nitrate/nitrite production and eNOS protein expression}

We studied the eNOS protein expression which is known to regulate NO production. It is apparent that eNOS protein expression in the thoracic aorta was decreased by $70 \%$ after L-NAME administration when compared with age-matched controls. Concomitant treatment with THC for 2 weeks, with either the low or high dose, significantly restored the eNOS protein expression $(P<0.05$, Figure 5a). Treatment with THC did not modify the level of eNOS expression in normotensive rats. Figure $5 \mathrm{~b}$ shows a significant reduction in plasma nitrate/ nitrite level of L-NAME-treated rats, confirming a reduction of NO production after L-NAME administration. Plasma nitrate/nitrite level significantly increased after THC treatment (Figure 5b).

Table 2 Effect of THC on oxidative stress and antioxidants status of rats in all experimental groups

\begin{tabular}{|c|c|c|c|c|c|}
\hline Group & $\begin{array}{l}\text { Superoxide production (counts per mg } \\
\text { dry weight per min) }\end{array}$ & Plasma MDA ( $\mu \mathrm{m})$ & $\begin{array}{l}\text { Plasma protein carbonyl } \\
\text { (nmol per mg protein) }\end{array}$ & GSH level $(\mu \mathrm{m})$ & GSH/GSSG \\
\hline \multicolumn{6}{|l|}{ Normotensive } \\
\hline Vehicle & $41.6 \pm 5.8$ & $5.7 \pm 0.5$ & $1.4 \pm 0.1$ & $614.4 \pm 26.7$ & $119.6 \pm 11.5$ \\
\hline THC $50 \mathrm{mg} \mathrm{kg}^{-1}$ per day & $44.3 \pm 3.2$ & $5.1 \pm 0.4$ & $1.1 \pm 0.1$ & $648.6 \pm 35.9$ & $116.8 \pm 10.8$ \\
\hline THC $100 \mathrm{mg} \mathrm{kg}^{-1}$ per day & $42.1 \pm 2.1$ & $5.0 \pm 0.3$ & $1.2 \pm 0.1$ & $639.3 \pm 18.8$ & $125.5 \pm 7.9$ \\
\hline \multicolumn{6}{|l|}{ L-NAME-induced hypertension } \\
\hline Vehicle & $224.9 \pm 10.3^{*}$ & $26.1 \pm 2.1 *$ & $2.6 \pm 1.6 *$ & $364.3 \pm 23.5$ & $54.5 \pm 5.2 *$ \\
\hline THC $50 \mathrm{mg} \mathrm{kg}^{-1}$ per day & $184.6 \pm 5.6^{*, \dagger}$ & $13.7 \pm 1.6^{*, \dagger}$ & $2.1 \pm 0.1^{*, \dagger}$ & $393.4 \pm 25.8^{*}$ & $67.5 \pm 6.6$ * \\
\hline THC $100 \mathrm{mg} \mathrm{kg}^{-1}$ per day & $173.5 \pm 9.7^{*, \dagger}$ & $11.8 \pm 0.5^{*, \uparrow, \ddagger}$ & $1.9 \pm 0.1^{*, \dagger, \ddagger}$ & $449.6 \pm 14.3^{*, \dagger}$ & $80.5 \pm 4.8^{*, \dagger}$ \\
\hline
\end{tabular}

Abbreviations: GSH, glutathione; GSSG, glutathione disulfide; MDA, malondialdehyde.

Values are expressed as mean \pm s.e.m., $n=8-10$ per group.

${ }^{*} P<0.05$ vs. normal control group. ${ }^{\dagger} P<0.05$ vs. L-NAME control group. ${ }^{\ddagger} P<0.05$ vs. L-NAME treated with THC $50 \mathrm{mg} \mathrm{kg}^{-1}$ per day. 


\section{DISCUSSION}

We have found that treatment with THC led to a significant reduction in the detrimental effect of L-NAME-induced hypertension in rats. THC was shown to reduce arterial blood pressure, improved hemodynamic status and aortic elasticity following chronic inhibition of NO synthesis. The ameliorating effects of THC might be mediated through its strong antioxidant property and its ability to partially induce the endogenous antioxidant system.

This study has confirmed that chronic L-NAME administration induces systemic hypertension and increases total peripheral resistance as a consequence of diminished NO production. ${ }^{29}$ The thoracic aorta from L-NAME hypertensive rats was shown to have been remodelled by hypertrophy and to have increased its functional stiffness ${ }^{30}$ and moderated its compliance. ${ }^{31}$ In addition, our present study revealed that arterial BP was elevated, whereas the aortic wall thickness was increased. These results indicate that the elevated BP may be causally related to the changes in vascular morphology and mechanical properties as a vascular adaptation to keep wall hoop stress at a

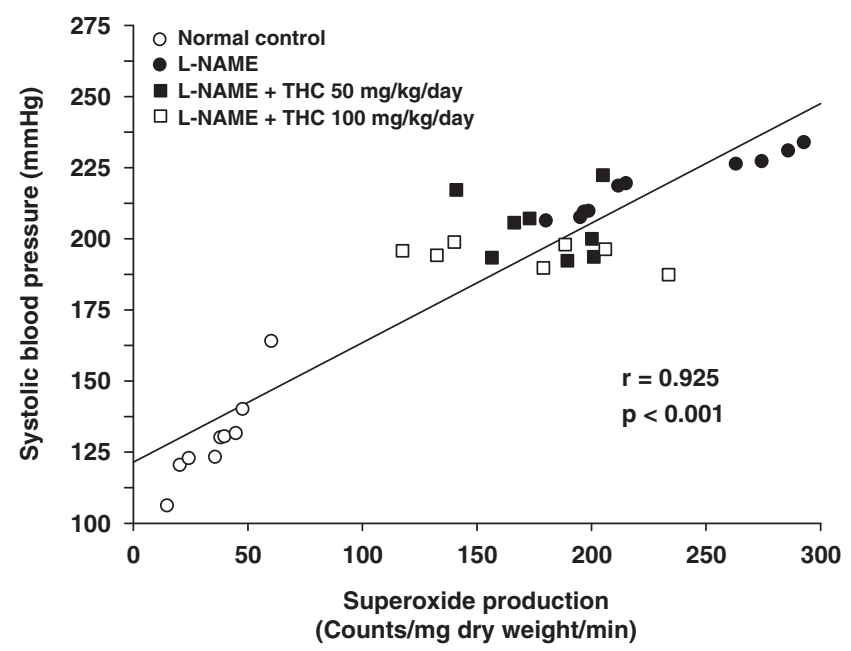

Figure 4 The relationship between systolic BP and superoxide anion production in the vascular tissue of all study animals. normal level. ${ }^{32}$ Vascular remodeling has been reported to be a consequence of a blockade of NO that leads to an abolition of the ability of the endothelium to protect against arteriosclerosis and to inhibit inflammation, smooth muscle cell proliferation and migration. ${ }^{33,34}$ Alternatively, the vascular remodeling might be influenced by an imbalance between oxidative stress and antioxidant. Excessive $\mathrm{O}_{2}^{\bullet-}$ production promotes vascular cell growth, inflammation and increased collagen deposition. ${ }^{35}$ Vascular remodeling is associated with altered mechanical properties, which might affect lumen diameter and consequently peripheral vascular resistance. ${ }^{36}$ We observed increased vascular stiffness accompanied by decreased blood flow and increased vascular resistance in rats treated with L-NAME.

Our data show that THC attenuated the elevation of BP in the hypertensive state without a hypotensive effect on normotensive animals. Overall, the results suggest that the effect of THC in moderating hypertension involved a reduction of total peripheral resistance. Moreover, THC treatment, especially at $100 \mathrm{mg} \mathrm{kg}^{-1}$, ameliorated vascular remodeling and the adverse hemodynamic status produced by chronic L-NAME administration. It seems likely that treatment with THC for a longer period of time than in the present study ( 2 weeks) may be able to further reduce high pressure and its deleterious consequences, as the fall in BP had shown no signs of plateauing at the end of the treatment period, (Figure 1). We did not continue the experiment for a longer period, because the L-NAME control rats were showing signs of severe morbidity.

We have demonstrated that L-NAME-induced high BP is associated with the overproduction of vascular $\mathrm{O}_{2}^{\bullet-}$. This overproduction may be due to an increase in NADPH oxidase activity, which is a major source of vascular $\mathrm{O}_{2}^{\bullet-}$ production. ${ }^{37}$ It has been suggested that a large amount of $\mathrm{O}_{2}^{\bullet-}$ production impairs NO bioavailability. ${ }^{3}$ The present results show decreased plasma nitrate/nitrite levels as well as a significant decrease of aortic eNOS expression in NO deficient rats. This is in agreement with previous studies that found decreased aortic eNOS mRNA and protein expression in rats receiving L-NAME. ${ }^{5,38-40}$ Decreased eNOS protein expression in this study might be due to the downregulation of eNOS gene expression. Conversely, other reports have shown that L-NAME induces an increased eNOS mRNA expression. ${ }^{41}$ It is therefore not easy to explain the discrepancy among these results. In any case, the decreased mRNA expression or decreased
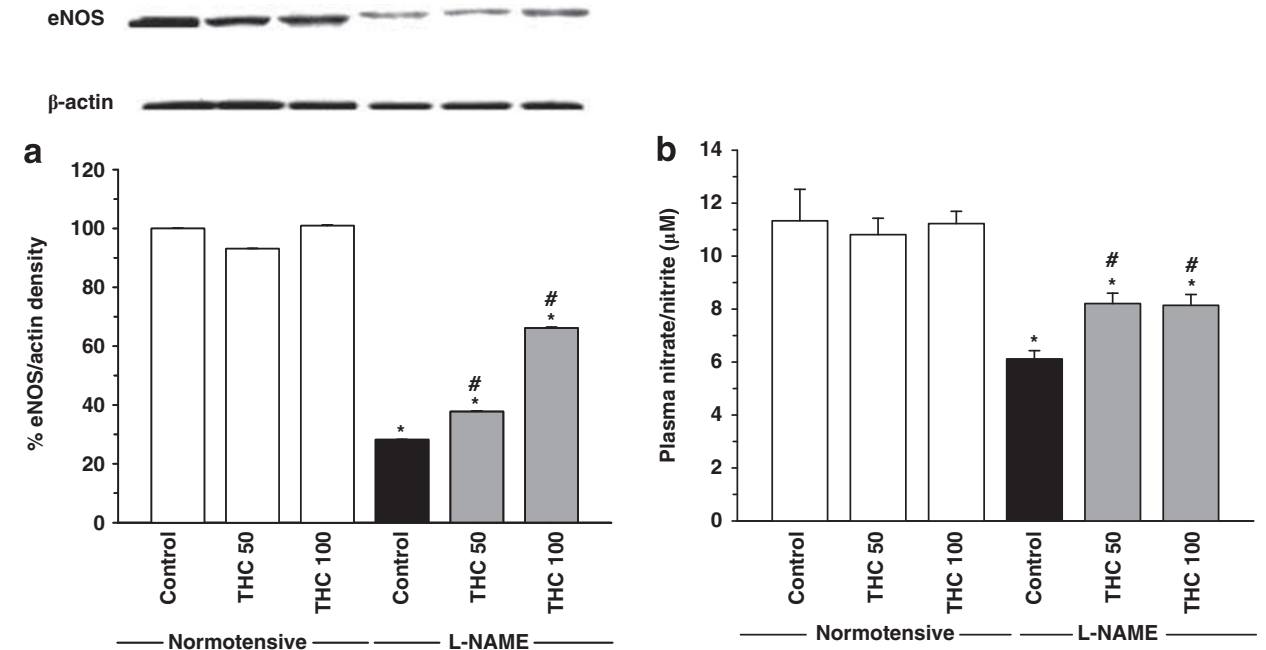

Figure 5 Effect of THC on a densitometric analysis and representative blot of eNOS protein expression in the thoracic aorta (a) and plasma nitrate/nitrite level (b) in all experimental groups. Results are expressed as mean \pm s.e.m. ( $n=6$ per group). ${ }^{*} P<0.05$ vs. normal control group, ${ }^{\#} P<0.05$ vs. L-NAME control group. 
nitric oxide synthase activity is consistent with our finding that there was a decreased eNOS protein expression in aortic tissues of L-NAME-treated rats.

Our study showed that THC significantly suppressed the overproduction of $\mathrm{O}_{2}^{\bullet-}$ and increased eNOS protein expression in the arterial tissues of L-NAME hypertensive rats. It has been reported that THC exerts its anti-inflammatory property by suppressing the activation of NF-kB through inhibition of IKK activity, ${ }^{42}$ although we did not examine NF-kB activation. Kitamoto et al..$^{43}$ have demonstrated that long-term inhibition of nitric oxide synthase increased the activity of NF-kB and AP-1 in the rat aortic wall. It is, therefore likely that the inhibition of NF-kB activation may lead to suppression of its downstream gene expression, particularly NADPH-oxidase. ${ }^{44-45}$ A downregulation of $\mathrm{NADPH}$-oxidase leads to decreased $\mathrm{O}_{2}^{\bullet-}$ production, and consequently, an increase in NO bioavailability decreased oxidative stress and inhibition of vascular remodelling. Moreover, THC may decrease reactive oxygen species by directly scavenging them and inducing the activity of endogenous antioxidant enzymes, including superoxide dismutase, catalase, GP $\times$ and GST. ${ }^{14,15}$ Previous studies have demonstrated that polyphenol could upregulate the eNOS expression of vascular cells by the activation of transcriptional factors of the proximal portions of the eNOS promoter, such as Sp1, GATA. ${ }^{46}$ This, therefore, might be a plausible mechanism for the increase in eNOS expression in vascular tissues after THC treatment.

The increased oxidative stress as demonstrated by a marked elevation of lipid peroxidation and protein oxidation in L-NAME-treated rats resulted in a reduction of GSH and the cellular redox status of GSH. THC may increase antioxidant enzyme expression and also decrease reactive oxygen species formation, as mentioned above. As a result, THC could substantially restore GSH to about $73 \%$ of control levels, whereas in the L-NAME-treated group the GSH level was down to $59 \%$ of control values. We note that GSH levels are still below the control level, as L-NAME was still administered to rats and oxidative stress was continued.

In conclusion, the present results demonstrate that THC partially reduces high BP in L-NAME-induced hypertensive rats. This was associated with an improvement of peripheral vascular resistance and aortic elasticity. The underlying mechanism might be partly due to the strong antioxidant properties of THC, including the suppression of $\mathrm{O}_{2}^{\bullet-}$ formation and enhanced antioxidant GSH, thereby increasing the NO bioactivity. Further studies are needed to elucidate the molecular and cellular mechanisms by which THC increases eNOS expression, whereas L-NAME is continuously inhibiting NO synthesis. The overall findings of this study support the idea of using THC as a dietary supplement to protect against adverse cardiovascular effects due to NO deficiency.

\section{ACKNOWLEDGEMENTS}

This study was supported by grants from the Faculty of Medicine, Khon Kaen University, and the Thailand Research Fund (Grant No. DBG5380045). Saowanee Nakmareong was supported by a CHE-PhD Scholarship, Commission on Higher Education, Ministry of Education, Thailand. We thank Professor Stephen E Greenwald, Barts and The London School of Medicine and Dentistry, Queen Mary University of London, for valuable suggestions on arterial elasticity measurement and language editing of the manuscript.

1 Gardiner SM, Compton AM, Bennett T, Palmer RM, Moncada S. Control of regional blood flow by endothelium-derived nitric oxide. Hypertension 1990; 15: 486-492.

2 Wilkinson IB, Franklin SS, Cockcroft JR. Nitric oxide and the regulation of large artery stiffness: from physiology to pharmacology. Hypertension 2004; 44: 112-116.
3 Torok J. Participation of nitric oxide in different models of experimental hypertension. Physiol Res 2008; 57: 813-825.

4 Rauchova H, Pechanova O, Kunes J, Vokurkova M, Dobesova Z, Zicha J. Chronic Nacetylcysteine administration prevents development of hypertension in N(omega)-nitro$\mathrm{L}$-arginine methyl ester-treated rats: the role of reactive oxygen species. Hypertens Res 2005; 28: 475-482.

5 Toba H, Nakagawa Y, Miki S, Shimizu T, Yoshimura A, Inoue R, Asayama J, Kobara M, Nakata T. Calcium channel blockades exhibit anti-inflammatory and antioxidative effects by augmentation of endothelial nitric oxide synthase and the inhibition of angiotensin converting enzyme in the $\mathrm{N}(\mathrm{G})$-nitro-L-arginine methyl ester-induced hypertensive rat aorta: vasoprotective effects beyond the blood pressure-lowering effects of amlodipine and manidipine. Hypertens Res 2005; 28: 689-700.

6 Yang HY, Yang SC, Chen ST, Chen JR. Soy protein hydrolysate ameliorates cardiovascular remodeling in rats with L-NAME-induced hypertension. J Nutr Biochem 2008; 19: 833-839.

7 Duarte J, Jimenez R, O'Valle F, Galisteo M, Perez-Palencia R, Vargas F, Perez-Vizcaino F, Zarzuelo A, Tamargo J. Protective effects of the flavonoid quercetin in chronic nitric oxide deficient rats. J Hypertens 2002; 20: 1843-1854.

8 Priviero FB, Teixeira CE, Claudino MA, De Nucci G, Zanesco A, Antunes E. Vascular effects of long-term propranolol administration after chronic nitric oxide blockade. Eur J Pharmacol 2007; 571: 189-196.

9 Yamashita T, Yamamoto E, Kataoka K, Nakamura T, Matsuba S, Tokutomi Y, Dong YF, Ichijo $\mathrm{H}$, Ogawa H, Kim-Mitsuyama S. Apoptosis signal-regulating kinase-1 is involved in vascular endothelial and cardiac remodeling caused by nitric oxide deficiency. Hypertension 2007; 50: 519-524.

10 Aggarwal BB, Sundaram C, Malani N, Ichikawa H. Curcumin: the Indian solid gold. Adv Exp Med Biol 2007; 595: 1-75.

11 Khopde SM, Priyadarsini KI, Guha SN, Satav JG, Venkatesan P, Rao MN. Inhibition of radiation-induced lipid peroxidation by tetrahydrocurcumin: possible mechanisms by pulse radiolysis. Biosci Biotechnol Biochem 2000; 64: 503-509.

12 Somparn P, Phisalaphong C, Nakornchai S, Unchern S, Morales NP. Comparative antioxidant activities of curcumin and its demethoxy and hydrogenated derivatives. Biol Pharm Bull 2007; 30: 74-78.

13 Naito M, Wu X, Nomura H, Kodama M, Kato Y, Kato Y, Osawa T. The protective effects of tetrahydrocurcumin on oxidative stress in cholesterol-fed rabbits. I Atheroscler Thromb 2002; 9: 243-250.

14 Murugan P, Pari L. Antioxidant effect of tetrahydrocurcumin in streptozotocin-nicotinamide induced diabetic rats. Life Sci 2006; 79: 1720-1728.

15 Pari L, Amali DR. Protective role of tetrahydrocurcumin (THC) an active principle of turmeric on chloroquine induced hepatotoxicity in rats. J Pharm Pharm Sci 2005; 8: $115-123$.

16 Ali MS, Mudagal MP, Goli D. Cardioprotective effect of tetrahydrocurcumin and rutin on lipid peroxides and antioxidants in experimentally induced myocardial infarction in rats. Pharmazie 2009; 64: 132-136.

17 Berry CL, Greenwald SE, Rivett JF. Static mechanical properties of the developing and mature rat aorta. Cardiovasc Res 1975; 9: 669-678.

18 Langewouters GJ, Wesseling KH, Goedhard WJ. The static elastic properties of 45 human thoracic and 20 abdominal aortas in vitro and the parameters of a new model. J Biomech 1984; 17: 425-435.

19 Greenwald SE. Pulse pressure and arterial elasticity. QJM 2002; 95: 107-112.

20 Luangaram S, Kukongviriyapan U, Pakdeechote P, Kukongviriyapan V, Pannangpetch P. Protective effects of quercetin against phenylhydrazine-induced vascular dysfunction and oxidative stress in rats. Food Chem Toxicol 2007; 45: 448-455.

21 Draper $\mathrm{HH}$, Hadley M. A review of recent studies on the metabolism of exogenous and endogenous malondialdehyde. Xenobiotica 1990; 20: 901-907.

22 Reznick AZ, Packer L. Oxidative damage to proteins: spectrophotometric method for carbonyl assay. Methods Enzymol 1994; 233: 357-363.

23 Sompamit K, Kukongviriyapan U, Nakmareong S, Pannangpetch P, Kukongviriyapan V. Curcumin improves vascular function and alleviates oxidative stress in non-lethal lipopolysaccharide-induced endotoxaemia in mice. Eur J Pharmacol 2009; 616: 192-199.

24 Verdon CP, Burton BA, Prior RL. Sample pretreatment with nitrate reductase and glucose-6-phosphate dehydrogenase quantitatively reduces nitrate while avoiding interference by NADP+ when the Griess reaction is used to assay for nitrite. Anal Biochem 1995; 224: 502-508.

25 Kukongviriyapan V, Somparn N, Senggunprai L, Prawan A, Kukongviriyapan U, Jetsrisuparb A. Endothelial dysfunction and oxidant status in pediatric patients with hemoglobin E-beta thalassemia. Pediatr Cardiol 2008; 29: 130-135.

26 Mukai Y, Sato S. Polyphenol-containing azuki bean (Vigna angularis) extract attenuates blood pressure elevation and modulates nitric oxide synthase and caveolin-1 expressions in rats with hypertension. Nutr Metab Cardiovasc Dis 2009; 19: 491-497.

27 Tietze F. Enzymic method for quantitative determination of nanogram amounts of total and oxidized glutathione: applications to mammalian blood and other tissues. Anal Biochem 1969; 27: 502-522.

28 Somparn N, Kukongviriyapan U, Tassaneeyakul W, Jetsrisuparb A, Kukongviriyapan V. Modification of CYP2E1 and CYP3A4 activities in haemoglobin E-beta thalassemia patients. Eur J Clin Pharmacol 2007; 63: 43-50.

29 Baylis C, Mitruka B, Deng A. Chronic blockade of nitric oxide synthesis in the rat produces systemic hypertension and glomerular damage. J Clin Invest 1992; 90: 278-281.

30 Pereira LM, Bezerra DG, Mandarim-de-Lacerda CA. Aortic wall remodeling in rats with nitric oxide deficiency treated by enalapril or verapamil. Pathol Res Pract 2004; 200: 211-217. 
31 Fitch RM, Vergona R, Sullivan ME, Wang YX. Nitric oxide synthase inhibition increases aortic stiffness measured by pulse wave velocity in rats. Cardiovasc Res 2001; 51: 351-358.

32 Hayashi K, Naiki T. Adaptation and remodeling of vascular wall; biomechanical response to hypertension. J Mech Behav Biomed Mater 2009; 2: 3-19.

33 Moncada S, Higgs A. The L-arginine-nitric oxide pathway. N Engl J Med 1993; 329 2002-2012.

34 Bernatova I, Pechanova O, Babal P, Kysela S, Stvrtina S, Andriantsitohaina R. Wine polyphenols improve cardiovascular remodeling and vascular function in NO-deficient hypertension. Am J Physiol Heart Circ Physiol 2002; 282: H942-H948.

35 Xu S, Touyz RM. Reactive oxygen species and vascular remodelling in hypertension: still alive. Can J Cardiol 2006; 22: 947-951.

36 Intengan HD, Schiffrin EL. Vascular remodeling in hypertension: roles of apoptosis, inflammation, and fibrosis. Hypertension 2001; 38: 581-587.

37 Gonzalez W, Fontaine V, Pueyo ME, Laquay N, Messika-Zeitoun D, Philippe M, Arnal JF, Jacob MP, Michel JB. Molecular plasticity of vascular wall during N(G)-nitro-L-arginine methyl ester-induced hypertension: modulation of proinflammatory signals. Hypertension 2000; 36: 103-109.

38 De Gennaro Colonna V, Rossoni G, Rigamonti A, Bonomo S, Manfredi B, Berti F, Muller E. Enalapril and quinapril improve endothelial vasodilator function and aortic eNOS gene expression in L-NAME-treated rats. Eur J Pharmacol 2002; 450: 61-66.

39 Simko F, Matuskova J, Luptak I, Krajcirovicova K, Kucharska J, Gvozdjakova A, Babal P, Pechanova O. Effect of simvastatin on remodeling of the left ventricle and aorta in L-NAME-induced hypertension. Life Sci 2004; 74: 1211-1224.
40 Nakmareong S, Kukongviriyapan U, Pakdeechote P, Donpunha W, Kukongviriyapan V, Kongyingyoes B, Sompamit K, Phisalaphong C. Antioxidant and vascular protective effects of curcumin and $\mathrm{n}$ in rats with L-NAME-induced hypertension. Naunyn Schmiedebergs Arch Pharmacol 2011; 383: 519-529.

41 Pechanova O, Bernatova I, Babal P, Martinez MC, Kysela S, Stvrtina S, Andriantsitohaina R. Red wine polyphenols prevent cardiovascular alterations in L-NAME-induced hypertension. J Hypertens 2004; 22: 1551-1559.

42 Pan MH, Lin-Shiau SY, Lin JK. Comparative studies on the suppression of nitric oxide synthase by curcumin and its hydrogenated metabolites through down-regulation of IkappaB kinase and NFkappaB activation in macrophages. Biochem Pharmacol 2000; 60: $1665-1676$

43 Kitamoto S, Egashira K, Kataoka C, Koyanagi M, Katoh M, Shimokawa H, Morishita R, Kaneda Y, Sueishi K, Takeshita A. Increased activity of nuclear factor-kappaB participates in cardiovascular remodeling induced by chronic inhibition of nitric oxide synthesis in rats. Circulation 2000; 102: 806-812.

44 Gauss KA, Nelson-Overton LK, Siemsen DW, Gao Y, DeLeo FR, Quinn MT. Role of NFkappaB in transcriptional regulation of the phagocyte NADPH oxidase by tumor necrosis factor-alpha. J Leukoc Biol 2007; 82: 729-741.

45 Anrather J, Racchumi G, ladecola C. NF-kappaB regulates phagocytic NADPH oxidase by inducing the expression of gp91phox. J Biol Chem 2006; 281: 5657-5667.

46 Wallerath T, Deckert G, Ternes T, Anderson H, Li H, Witte K, Forstermann U. Resveratrol, a polyphenolic phytoalexin present in red wine, enhances expression and activity of endothelial nitric oxide synthase. Circulation 2002; 106: 1652-1658. 